\title{
O corpo como fio condutor para ampliação da clínica ${ }^{1}$
}

Body as a conducting wire for extension of clinic

El cuerpo como hilo conductor para la ampliación

de la clínica

\section{Dagoberto de Oliveira Machado}

Universidade Federal do Rio Grande do Sul, Porto Alegre, RS, Brasil.

Michele de Freitas Faria de Vasconcelos

Universidade Federal do Rio Grande do Sul, Porto Alegre, RS, Brasil.

Aldo Rezende de Melo

Universidade Federal do Sergipe, Aracaju, SE, Brasil.

\begin{abstract}
Resumo
O texto tem como objetivo ampliar a diretriz da clínica ampliada nos termos definidos pela Política Nacional de Humanização. Numa tentativa de arejamento e atualização de tal diretriz, toma o corpo como um operador da ampliação da clínica. Para tanto, partiu-se de itinerários foucaultianos e nietzscheanos, de experimentações desenvolvidas a partir de nossas inserções na rede de saúde mental do município de Aracaju-Sergipe, bem como dos dados produzidos por nossas pesquisas de mestrado e doutorado. Entendendo corpo como uma montagem, como uma feitura realizada num espaço de tensão entre formas de sujeição e forças de experimentação, se pensou a própria clínica como um corpo. Clínica-corpo que se traceja por entre desejos de formatação, mas também uma clínica que (re)existe, mais afeita à abertura dos corpos, inclusive o seu próprio.
\end{abstract}

Palavras-chave: Corpo, Clínica, Clínica Ampliada, Saúde Mental, Reforma Psiquiátrica/CAPS.

\footnotetext{
Abstract

This paper aims to widen the extended clinic guideline as defined by the National Humanization Policy. In an attempt to aerate and update such guideline, it takes the body as an operator for the extension of the clinic. Therefore, we start from Foucauldian and Nietzschean itineraries, of experimentation developed from our inserts in mental health system of the city of Aracaju, Sergipe, and the data produced by our masters and doctoral researches. Understanding body as an assembly, as a workmanship made in a space of tension
} 
between forms of subjection and experimentation forces, it was thought the clinic as a body; clinic body traced through formatting desires, but also a clinic that re-exists, preferring the opening of bodies, including its own.

Keywords: Body, Clinic, Extended clinic, Mental Health, Psychiatric Reform.

\section{Resumen}

El texto tiene como objetivo ampliar la directriz de la clínica ampliada en los términos definidos por la Política Nacional de Humanización. En un intento de aireamiento y actualización de tal directriz, toma el cuerpo como un operador de la ampliación clínica. Para tanto, se partió de itinerarios foucaultianos y nietzscheanos, de experimentaciones desarrolladas a partir de nuestras inserciones en la red de salud mental en el municipio de Aracaju - Sergipe, así como de los datos producidos por nuestras investigaciones de máster y doctorado. Entendiendo cuerpo como un montaje, como una fabricación realizada en un espacio de tensión entre formas de sujeción y fuerzas de experimentación, se pensó la propia clínica como un cuerpo. Clínica-cuerpo que se traza por entre deseos de formateo, pero también una clínica que re-existe, más habituada a la apertura de los cuerpos, incluso su propio.

Palabras-clave: Cuerpo, Clínica, Clínica Ampliada, Salud Mental, Reforma Psiquiátrica/ CAPS.

Os fios que tecem essa escrita foram alinhavados por meio de nossas itinerâncias na rede de saúde mental de Aracaju-Sergipe como trabalhador/a, gestor/a, pesquisador/a. Desse percurso, pinçamos aqui experimentações de modos de fazer clínica, na direção de empreender discussões sobre o caso da clínica em saúde mental.

Seguindo uma pista nietzschiana (1885/2008), optamos aqui por tomar o corpo como fio condutor de análises sobre a clínica. A proposta do presente texto traduz-se, assim, por pensar o corpo como um operador para ampliação da clínica. Entendendo corpo como uma montagem, como uma feitura realizada, como aponta Paraíso (2011), num espaço de tensão entre formas de sujeição e forças de experimentação, pode-se pensar a própria clínica como um corpo. Clínica-corpo que se traceja por entre desejos de formatação, mas também uma clínica que (re)existe, mais afeita à abertura dos corpos, inclusive o seu próprio. 
A tentativa foi a de rastrear em nossas andanças pela saúde mental esses momentos singulares de dispersão da clínica, seguir movimentos de uma clínica artesanal, ensaística, ainda que ampliada, minimalista, circunstancial, não generalizável. Está-se apostando, pois, na clínica como espaço de experimentação.

Para nós, a diretriz da Clínica Ampliada proposta pela Política Nacional da Humanização (Brasil, 2008) parece apresentar indicativos de necessidade de atualização. Como caminhinhos de ampliação, tal diretriz aponta para: 1) visar a saúde, e não a doença, como objeto de investimento, "considerando a vulnerabilidade, o risco do sujeito em seu contexto" (p. 55); 2) produzir saúde, aumentando autonomia dos sujeitos; 3) fazer avaliação diagnóstica a partir do saber técnico e epidemiológico, mas também da história do sujeito e seus saberes; 4) definir a terapêutica, considerando a complexidade das demandas de saúde.

Partindo dessas propostas e
percorrendo novos caminhos,
vislumbramos como crucial para o
processo de ampliação da clínica o
deslocamento de territórios existenciais por
meio de encontros entre corpos que
acontecem no terreno da clínica como
campo de experimentação. Ora, ampliamos

a clínica por necessidades de (trans)formação do corpo, inclusive do corpo da clínica, por necessidade de desfazer o já dado sobre uma clínica predominantemente verbal e colada a um corpo entre o biológico e a linguagem, para nos remeter a um corpo-larvário, inominável, ilocalizável, impossível, não dado, ao poroso vazio do não saber sobre o que é um corpo e sobre suas infindáveis formas de feitura. Mesmo assim, almejamos segui-lo, rastreá-lo, pois o importante é tentar mesmo o impossível (Amado, 1961/2008). Ressalte-se aqui uma passagem de Foucault sobre corpo (Foucault, 2001a, p. 20):

\begin{abstract}
[...] sobre o corpo se encontra o estigma dos acontecimentos passados do mesmo modo que dele nascem os desejos, os desfalecimentos e os erros; nele também eles se atam e de repente se exprimem, mas nele também eles se desatam, entram em luta, se apagam uns aos outros e continuam seu insuperável conflito.
\end{abstract}

Para Foucault (2001a), o corpo é inteiramente marcado e arruinado pela história, uma história entendida como "o próprio corpo do devir" (Foucault, 2001a, p. 20), composta mais por rupturas, descontinuidades, do que por uma pretensa linearidade. Nesse sentido, o mesmo corpo marcado pela história de um tempo, 
superfície desenhada por inscrições sócioculturais (de raça-cor-etnia, de gênero e sexualidade, de classe social, de religião, de geração etc.), é também um corpo que tende a (re)existir: "superfície de inscrição dos acontecimentos (enquanto a linguagem os marca e as idéias os dissolvem), lugar de dissociação do Eu (que supõe a quimera de uma unidade substancial) volume em perpétua pulverização" (Foucault, 2001a, p. 22).

Nessa direção de pensar arranjos corporais que resistem a formatações inclusive clínicas, é que nos parece que buscar por essas feituras pode ser uma pista importante quando o que se intenta é ampliar a clínica, pois uma ampliação "que não se limite à criação de um novo clichê referendo de velhos especialismos - parece mesmo requerer esforços teóricos, éticos e políticos que extrapolam em muito meras respostas às ampliações das demandas para o trabalho clínico que o contemporâneo também impõe" (Paulon, 2004, p. 264).

Nesses tempos de "subjetividade exteriorizada" (Ortega, 2008), em que saúde tende a se traduzir em corrida pela perfeição corporal, em que a apresentação corporal parece dizer o que são as pessoas, quando se pensa a ampliação da clínica por meio do operador corpo, é preciso, pois, questionar as encomendas institucionais acerca da clínica e do corpo nos processos de trabalho em saúde. Por meio das práticas de saúde, que feituras corporais têm sido fabricadas?

Nesses tempos em que os sujeitos e seus corpos, para participar da economia social de mercado, devem se construir como empreendedores de si, as práticas clínicas tendem a se traduzir em práticas especialistas no empreendimento de formatação corporal e subjetiva. Nesse sentido, pode-se dizer que práticas clínicas tendem a funcionar no seio de um exercício de poder que, tendo a vida como objeto, pretende iluminar excessivamente as carnes (Foucault, 2006), produzindo corpos organizados, organizando inclusive corpos tidos como anormais, pois estes também devem estar na norma (VeigaNeto, 2001). Articulando-se à lógica da necessária intervenção sobre corpos abjetos (Louro, 2004) - corpos que, ao mesmo tempo, indicam o limite que os corpos saudáveis não devem ultrapassar e precisam ser corrigidos, normalizados $-\mathrm{a}$ clínica, por sua vez, em muito ainda parece funcionar ainda nesse sentido de clareamento e cerceamento dos corpos e seus movimentos.

Desse modo, pode-se questionar: se é no interior de uma rede de práticas que se engendra um rosto específico para o objeto corpo saudável, as práticas clínicas podem escapar da encomenda de 
produzir/sustentar tal rosto? Podem-se maquinar outros processos de trabalho, outros corpos, outras saúdes, outras clínicas? Se sim, de que modo?

A partir de nossas experimentações, inclusive conceituais, apostamos que o corpo pode ser um operador importante na direção de construção de linhas de fuga para o que está naturalizado no terreno do cuidado em saúde. Desse modo, uma pergunta aparece forçando um pensamento intempestivo capaz de produzir estranhamento: como dar corpo a outras práticas clínicas? Espreitando insistentemente o cotidiano de serviços de saúde mental, nos deparamos com movimentos de (re)existência da clínica: uma clínica das passagens corporais, tecida bem ali onde territórios existenciais se compõem dobrando as esquinas desse exercício de poder intitulado por Foucault (2001b) de biopoder.

\section{Corpo intercessor}

Conforme já registrado, o objetivo dessa montagem textual é operar com o conceito de corpo como intercessor (Deleuze, 1992), ou seja, por meio dele interceptar, derivar, desviar, correlacionar, intervir no modo de pensar e fazer clínica. Nesse sentido, ele, enquanto intercessor de nossas práticas clínicas, é fio condutor de nossas análises sobre a ampliação da clínica.

Nesse texto, entende-se corpo como construto político-cultural e o fazer em saúde como instância pedagógica por meio da qual se tende a imprimir no mesmo marcas sociais, identificando-o e fixandoo. Nesse sentido, Meyer (2009, p. 128) afirma que o corpo é produzido em redes de significação, na articulação entre nossas "heranças genéticas" e "aquilo que aprendemos quando nos tornamos sujeitos de uma cultura". Louro (2004, p. 89), por sua vez, assinala que: "nomeados e classificados no interior de uma cultura, os corpos se fazem históricos e situados. Os corpos são 'datados', ganham um valor que é sempre transitório e circunstancial". Inseridos num contexto histórico-políticocultural específico, os corpos são, então, fabricados por variadas marcações: de gênero, de sexualidade, de classe social, de raça/cor, de religião, de faixa etária, de geração, de região etc. Corpos são montados e organizados por tais "marcas de poder", a partir das quais, "podem valer mais ou menos" (Louro, 2004, p. 89).

A direção é, então, a de problematização e desnaturalização da concepção de corpo como dado, evidência, como objeto natural, como substância, à ideia de um corpo essencial, único e imutável, que pudesse condensar traços de 
tantos outros e, a partir dele, se pudesse almejar uma pretensa universalidade. Não existe o objeto natural corpo, não existe "o" corpo. "O corpo é uma falsa evidência" (Le Breton, 2007, p. 26).

Todavia, além de construto político-cultural, corpos são construções político-éticas. Mais do que afeitos à submissão a determinadas pedagogias culturais e à toxicomania identitária que lhes organizam, lhes marcam, lhes ensinam 'boas' condutas e avaliam seu valor, os corpos tendem à singularização. Situandose em fendas do jogo do poder, abandonam a adesão obediente às fôrmas subjetivas prescritas por tais pedagogias, recusam o que são e ensaiam a invenção de outros modos de existir (Guattari \& Rolnik, 2000).

\section{Corpos e práticas que brotam da repetição}

Em substituição ao modelo asilar de tratamento, a Política Nacional de Saúde Mental/SUS preconiza que as pessoas com transtornos mentais graves e/ou persistentes bem como pessoas com sofrimentos decorrentes do uso prejudicial de álcool e outras drogas devem ser cuidadas em serviços substitutivos de saúde mental. Tais serviços prestam uma assistência de base comunitária inseridos nos territórios geográficos em que os/as usuários/as residem. Desse modo, os Centros de Atenção Psicossocial (CAPS), responsáveis por tecer a rede de cuidado em saúde mental, passam a funcionar como ordenadores desta rede (Brasil, 2002).

Inseridos nos CAPS, usuários/as egressos/as de longos períodos de internação psiquiátrica costumam se apresentar cronificados/as. O modo de andar, de sentar e deitar no chão, a repetição dos gestos, das falas, o ato de tirar a roupa, de caminhar descalço, o fumar compulsivo, o olhar fixo no horizonte parecem compor sinais corporais aprendidos por meio de uma pedagogia silenciosa, reiterada, desenvolvida em longos processos de internação em clínicas e hospitais psiquiátricos. Tais gestos costumam acompanhar o corpo de usuários/as advindos/as de longos períodos de internação nesses espaços, conformando uma produção cronificada do processo de adoecimento.

A intervenção nesta configuração corporal desenha-se como um dos grandes desafios do processo de trabalho dos serviços substitutivos de saúde mental. Os usuários cronificados costumam apresentar dificuldade de adesão e permanência nas ofertas de cuidado realizadas pelo serviço. Os usuários moradores dos Serviços Residenciais Terapêuticos $(\mathrm{SRT})^{2}$, em sua 
maioria, correspondem a esse perfil.

Com os CAPS, os muros físicos dos hospitais caíram. Porém, outros muros, quiçá corporais, foram inscritos nas carnes destes/as usuários/as e nas de profissionais de saúde, de tal forma que continuam a instalar dificuldades de encontro e afetação entre corpos.

Sob o rótulo de embotamento afetivo, muitos/as acreditam não haver meio de composição com estes corpos cronificados. Entretanto, experimentando aquela modalidade de atenção cartográfica indicada por Kastrup (2007), ao seguir suas pegadas, tateando suas peles, a força de expressão desses corpos, sua afetividade e seus gestos, parece ser outra: expressão por intensidades. Ao traçarem suas linhas, fluxos que, aparentemente, são apenas repetição, "nunca passam pelo mesmo lugar”, produzem diferença em cada gesto (Deleuze \& Guattari, 1997).

“Pá, pá, pá, pá, pá, pá, Pá”. Usuário, negro, homem, egresso de um longo caminho de internações psiquiátricas, morador de uma residência terapêutica, segue caminhando sem parar pelo CAPS. Repetindo sempre as mesmas sílabas, risca as paredes fazendo signos sem sentido. Gestos e língua que conservam a força de uma repetição, mas que, a cada movimento, produzem diferenciação. No álbum intitulado Nome,
Arnaldo Antunes (1993) canta esse “Agora”: “Já, já, Já, Já pá, já pá, pás, já pás, pás, passou, já passou, já, passou, já passou, já pá, Pá, pá, pá, sou, já, pá, sou, sou, s, sou, sou, já, já passou, pá, já passou". Num processo de repetiçãodiferenciação, esse corpo-usuário gagueja sua língua e seu corpo, já passou. Como conservar forças se não por uma repetição que, ao invés de reproduzir, parece introduzir a diferença?

Quando se referem a esses/as usuários/as cronificados/as, profissionais costumam relatar: "ele não gosta de fazer nada", "não tem vontade de nada", "fica aí parado, ou fica aí andando pra lá e pra cá”, "fica repetindo sempre a mesma coisa". O que pode indicar esta vontade de nada? Esse ficar parado? Esse vai e vem no caminhar de muitos/as usuários/as? Essa vontade de nada que os/as trabalhadores/as sinalizam indicaria um entorpecimento do corpo? Com que função? Um niilismo destrutivo ou um movimento de sobrevivência como resistência do próprio corpo?

Para Nietzsche, uma vontade de nada ainda é melhor do que um nada de vontade, posto que ainda há a vontade (Giacoia Jr., 2001). O que esta força da repetição corporal conserva e introduz de novo na cena instituída do corpo-loucocronificado? Como bifurcar bem ali onde 
parece não se ter mais nada a fazer?

Ensaiando situar nossas análisesintervenções para além de prescrições corporais como também além da desistência de investimento para encontrar com corpos que operam práticas de si, de mundo, de coletivos, abrem-se possibilidades outras de entendimento da cronicidade de gestos de alguns/umas usuários/as. Nessa direção, os movimentos repetitivos dos/as usuários/as cronificados/as, que parecem não dizer nada mais do que apenas o resultado de um processo de institucionalização, podem ser considerados como possuindo uma função, como ato técnico do corpo. Se “o corpo é o primeiro e mais natural objeto técnico e ao mesmo tempo o meio técnico é homem" (Mauss, 1974, p. 217), se o "corpo é marcado e arruinado pela história", mas também é "superfície de inscrição dos acontecimentos" (Foucault, 2001a), podese entender os movimentos corporais repetitivos dos/as usuários/as como compondo um processo de subjetivação, uma "dobra" que se apresenta no corpo na forma de técnicas corporais. Parece que a potência desses corpos está no ato de produzir uma dobra da dobra, fazendo, assim, acontecer nessa repetição outros corpos, outras práticas, outros movimentos.

Quando as forças do fora forçam a desterritorialização, pode-se maquinar, por entre linhas de fuga, um Corpo sem Órgãos (CsO). Seria o corpo cronificado um $\mathrm{CsO}$, do qual falam Deleuze \& Guattari (1996) em Mil Platôs? O qual nos expõe Artaud (1983) através do seu teatro contra a organização dos $\operatorname{organismos}^{3}$ ? Pois é contra o julgamento, a organização, os estratos, contra o juízo que um Corpo sem Órgãos é criado. Criar para si um $\mathrm{CsO}$ parece ser, pois, uma questão de vida. $\mathrm{O}$ $\mathrm{CsO}$ do corpo cronificado, por que ainda seria uma questão de vida no território do CAPS? Por que ainda seria necessária essa montagem corporal? Nesses poucos anos de experimentação de um cuidado em saúde mental que tem o CAPS como ordenador, como se tem lidado com os corpos cronificados? As práticas de cuidado tem deles se investido? De que maneira?

A partir de tais considerações, temos uma única certeza: “jamais saberemos integralmente o que pode um corpo, pois ele é absolutamente paradoxal" (Giacoia Jr., 2002, p. 214). Se "cartografar é sempre compor com um território existencial, engajando-se nele" (Alvarez \& Passos, 2009, p. 131), uma pista importante pode ser a de compor novos elementos na linha de cuidado desses corpos, entendendo-os como possíveis de intercessão e intervenção, no sentido que Deleuze (1992) e Lourau (1995) dão a 
esses termos: produção de perturbação no que parece óbvio e composição de territórios de habitação comuns entre corpos. Nesse sentido, a proposta é a de experimentação de um cuidado singularizante, de uma intervenção que por intercessão, no encontro com eles, produza variações no próprio corpo da clínica.

\section{A ambiência como passagem entre espaço, corpo e clínica}

Nos serviços de saúde mental, onde os/as usuários/as cronificados/as costumam ficar? Que espaços do CAPS eles habitam? De que modo? Em nossas itinerâncias pela rede de saúde mental aracajuana, observamos que esses usuários/as tendiam a habitar um "espaço morto" no interior dos serviços, ali passando os dias, participando pontualmente das atividades ofertadas pelo serviço Munido/a dessas observações e de desejos de interferência nesse contexto, construiu-se um território de habitação coletiva bem no meio de um desses espaços "mortos", aparentemente sem vida.

Ao longo do ano de 2007, acompanhando a direção da gestão de saúde mental que apontava a necessidade de qualificação do cuidado prestado pela rede psicossocial, a equipe técnica de um
CAPS três $24 \mathrm{~h}^{4}$ iniciou uma discussão que mirava um processo de planejamento e implementação das atividades terapêuticas ofertadas pelo serviço, o que passou por discutir seu cardápio de oficinas terapêuticas ${ }^{5}$.

Num primeiro momento da discussão, que ocorrera ao longo de algumas reuniões de equipe técnica, profissionais responsáveis pela condução das oficinas apresentaram cada oficina ofertada. Percebeu-se que usuários/as em crise, com determinadas limitações físicas e/ou cognitivas, cronificados, moradores dos SRTs e usuários/as em acolhimento noturno costumavam não participar das oficinas. Isso sinalizava para a equipe uma paisagem de cuidado que parecia não acolher os casos de maior necessidade de intervenção. Despontava-se, assim, a necessidade de analisar, interferir e modificar tal paisagem.

Dessa forma, iniciou-se o segundo momento da discussão, em que foi preciso pensar e apresentar alterações na oferta de cuidado, inserindo novos elementos nas oficinas existentes e criando novas oficinas, pautando-se, para isso, nas demandas dos/as usuários/as. Nesse contexto, foi proposta pelo Projeto Movimentos uma oficina modular de capoeira.

Nesse CAPS, tem-se um corredor 
que parte da recepção, prolongando-se até os fundos do estabelecimento. Ao final do corredor, abre-se um espaço amplo, conformando o centro do serviço, local de maior fluxo e permanência de usuários/as. O mesmo é utilizado como refeitório, sendo preenchido por algumas mesas e bancos, em que os/as usuários/as ficam sentados, conversando, andando, fumando, esperando pelas atividades. Por ali também circulam trabalhadores/as. Trata-se de um espaço sempre ocupado por corpos em passagem em suas produções cotidianas. As únicas pessoas que parecem ali se grudar são os/as usuários/as cronificados em seus delírios e alucinações, sentados, deitados, gritando, falando coisas, em seus movimentos repetitivos.

Este espaço aberto no meio do serviço funciona como uma espiral, em que os corpos entram, rodam e são jogados para fora novamente. Um não-lugar ${ }^{6}$ dentro do serviço. Seu potencial de produção de encontros e realização de atividades terapêuticas parece ser desconsiderado pelos/as profissionais "porque é muito quente", "porque faz muito barulho", "porque tem muita gente passando". Além da realização de refeições, esse espaço reserva-se para a realização da assembléia com usuários e de confraternizações, ocasiões em que um grande número de pessoas ocupa o serviço.
Pensar, pois, os espaços físicos dos serviços a partir da diretriz de ambiência (Brasil, 2010) requer alguns deslocamentos: não se trata apenas da distribuição de corpos em um dado espaço físico, mas sim, de como se dá a relação dos corpos com o espaço, as possibilidades de circulação dos mesmos, a convivência entre os corpos, o modo de habitação do espaço e, nestes processos, a produção dos próprios corpos. Nesse ponto se articula espaço, corpo e clínica: se intentarmos a desinstitucionalização do cuidado em saúde mental, parece ser importante que faça parte de nossas análises e intervenções se pensar sobre os usos e os modos de habitação dos espaços de um CAPS espaços como produtores do processo de cuidado. Isso porque há uma íntima relação entre espaço, corpo e clínica que não podemos desconsiderar.

Nessa direção, alterar a ambiência seja por meio de reformas estruturais necessárias, seja por meio de experimentação de novos modos de habitação de um espaço tido como "morto" como o refeitório de um CAPS, enfim, nos parece um item importante a ser levado em consideração quando o que se quer é produzir mudanças nos processos de trabalho rumo à qualificação do cuidado. 


\section{A roda: dando passagens ao corpo, ao}

\section{CAPS, à clínica}

Conforme já mencionado acima, a oficina modular de capoeira proposta pelo Projeto Movimentos foi programada para se realizar justamente nesse espaço central utilizado como refeitório e como estada de corpos cronificados. A proposta foi, então, apresentada aos/às usuários/as. O objetivo é que ela ocorresse durante dois meses, porém, por solicitação de usuários/as, foi estendida por mais um mês.

As atividades eram planejadas segundo as demandas apresentadas nos Projetos Terapêuticos Singulares e as necessidades observadas ao longo da própria oficina. As práticas eram coletivas, começando por um alongamento dirigido, depois por um aquecimento com movimentos básicos, principalmente movimentos de ginga e deslocamento. Em toda aula, havia a repetição da série de movimentos aprendida na aula anterior, acompanhada pela introdução de algum elemento novo. No segundo momento da aula, a turma era divida em duplas, para que os movimentos realizados individualmente nos exercícios anteriores fossem experimentados a partir de uma seqüência desenvolvida agora pela dupla. No final da aula havia sempre uma roda para que os movimentos pudessem ser experimentados no jogo. Depois que todos haviam jogado, era realizado um momento de relaxamento, em que os usuários deitavam em colchonetes e recebiam comandos de voz para que começassem a relaxar e coordenar a respiração. Por meio de toques nas articulações, iam relaxando o corpo. No momento final, era realizada outra roda, agora de conversa sobre a aula. Nela, cada usuário/a podia falar sobre como experimentou as atividades, dificuldades, superações, sensações.

Com inserções variadas, entradas e saídas diversas, usuários/as foram aderindo à oficina. A roda, geradora de uma força atrativa, parecia puxar para o centro do jogo as intensidades dos corpos. Atravessava-os com linhas, que iam engendrando participações tão diversas, que não se resumiam ao jogo no centro da roda. No decorrer da oficina de capoeira, observa-se que alguns/mas usuários/as que não faziam fisicamente a capoeira (não exercitavam), estavam presentes e envolvidos/as com a atividade, participando, gingando com o olhar. Entravam em outro ponto do jogo: aprendiam pelo olhar, olhando os/as colegas, acompanhando com palmas, atentos/as aos movimentos, pedindo silêncio para os/as outros/as que passavam ou chegavam desavisados/as do que estava ali se desenvolvendo. 
Uma das usuárias observava todas as aulas. Às vezes, esboçava um sorriso ou acompanhava com uma palma. Mantinha os olhos atentos ao movimento que os corpos desenhavam em cada jogo, em cada roda que se formava. Seu corpo jogava com o corpo do outro, no movimento do outro. Algumas vezes foi convidada para entrar na roda ou participar de alguma atividade, tendo-se sempre uma negativa como resposta. No entanto, permanecia ali, jogando com os olhos.

Durante as atividades, observaramse algumas rodas concêntricas se formarem em torno do jogo: havia os dois jogadores no centro da roda, gingando em movimentos cadenciados pelo ritmo das palmas, do berimbau e das músicas. Havia a roda formada pelos usuários que participavam oficialmente das atividades. Outra, aberta e dispersa, se formava de maneira aleatória por usuários que assistiam ao jogo, acompanhando com palmas. Havia ainda, os trabalhadores que, em alguns momentos, ao passarem pelo refeitório, eram capturados pela roda, interrompendo sua trajetória, sendo impelidos a observar o jogo. Por meio da composição dessas rodas, a prática da capoeira funcionou como agenciadora de encontros com corpos e entre corpos, de encontros com o outro dos corpos.

Por meio de sua participação na oficina, a presença de usuários/as cronificados/as no espaço morto do refeitório parecia ser reconfigurada. Ao se ver corpos se movimentarem diferentemente do se que estava descrito e prescrito em seus prontuários ou do que indicava a caracterização de suas patologias e suas próprias condutas cotidianas, produziu-se estranhamento de outros/as usuários/as e trabalhadores/as.

A oficina de capoeira funcionou, assim, como analisadora da suposta não adesão de usuários/as cronificados/as às atividades propostas e da também suposta inadequação deste espaço central para a realização de atividades terapêuticas. O corpo desses/as usuários/as e o não-lugar do refeitório ganharam novos contornos com as atividades da capoeira. A oficina de capoeira pareceu, assim, constituir um território existencial coletivo desfazendo o aparentemente óbvio da mortificação daquele espaço e dos corpos que ali faziam morada. Nesse sentido, pode-se dizer que a oficina introduziu uma mudança na ambiência do lugar, funcionando como um outro modo de articulação entre espaço, cuidado e corpo, como uma via de passagem para forças que habitavam a virtualidade desse território existencial composto pelo cruzamento entre espaço e esses corpos cronificados bem como entre espaço e a cronificação das próprias 
atividades ofertadas, no sentido de que as mesmas tendem a não fazer sentido para esses corpos.

Entra na roda um corpo adolescente com cerca de 20 anos, esquizofrênico. Um corpo de difícil comunicação com outros, um corpo que não olhava nos olhos, um corpo que parecia se conformar com aquele tradicional sinal de embotamento afetivo. Mas, na roda de capoeira, para não levar rasteira, é preciso olhar no olho do outro e da roda, é preciso gingar, se afetar, e esse corpo olhou, gingou, sorriu, se afetou. Durante os jogos de capoeira, aqueles olhos que nunca olhavam diretamente nos olhos do outro, agora não desviavam o olhar, pois era preciso jogar. Encontro intensivo entre corpos, afeto, composição, em que a "relação sujeitoobjeto treme", algo passa entre os movimentos, introduzindo o novo, a novidade, o larvário (Orlandi, 2009).

Desse modo, parece ter acontecido um deslocamento do que se concebia capaz àquele corpo-esquizofrênico, olhardistante. Não cabia mais classificar a (falta de) comunicação do seu olhar. Ele parecia não caber mais no corpo que tinha antes, ganhando volume, outras formas, outros movimentos. Novos modos de conexão foram experimentados com seu corpo, novos agenciamentos, quando agenciar é experimentar um máximo de conexões
(Escóssia, 2009): conexão com o olhar, com seu próprio corpo, com o corpo do outro, conexão com o jogo, conexão com a roda. O que se sabia sobre ele mudou, passou, outro corpo emergiu. Outras conexões se faziam necessárias.

Corpos não se reduzem a estratos, mas podem partir deles para produzirem um novo território, uma casa, uma dobra sobre si. Por meio de seus movimentos, corpos que participavam da roda, mesmo que não diretamente jogando, pareciam (re)existir em outro território que não apenas o do corpo cronificado. A capoeira praticada por corpos desacreditados naquele lugar desacreditado (refeitório) produziu uma ruptura dos estratos e uma abertura nos corpos cronificados bem como no corpo de um cuidado também cronificado, colado a pedagogias corporais que perpetuavam as condutas costumeiras de tais corpos cronificados, naquele espaço que era considerado um espaço morto que alojava corpos-vivos. No campo do visível e do enunciável sobre corpos cronificados, emergiu um corpo inédito, mudando o plano de visibilidade e dizibilidade sobre tais corpos. Houve uma disjunção, uma ruptura entre o que era dito sobre eles, nos prontuários, descrições psicopatológicas, naquilo que cotidianamente se esperava de suas condutas e aquilo que agora se torna visível no "quadro-visibilidade" (Deleuze, 
2005).

\section{Os CAPS como territórios de ensino e} (des)aprendizagens corporais ${ }^{7}$

No início dos anos oitenta, em um dado momento do desenvolvimento de suas pesquisas, na busca por caminhos para extrapolar a crítica de que o sujeito por ele pensado seria efeito apenas de relações de dominação, Foucault (2011) faz um deslocamento na chave de compreensão das relações de poder, entendendo-as, a partir de então como relações de governo:

[...] tentei esboçar um pouco essa noção de governo que me pareceu ser muito mais operatória que a noção de poder; governo entendido seguramente não no sentido restrito e atual de instância suprema de decisões executivas e administrativas em um sistema estatal, mas no sentido largo e antigo de mecanismos e procedimentos destinados a conduzir os homens, a dirigir a conduta dos homens, a conduzir a conduta dos homens (Foucault, 2011, p. 53).

Na medida em que são necessários investimentos educacionais ${ }^{8}$ para formar sujeitos governáveis, que, nos dias atuais, se traduzem em empresários de si ou, ainda, para (re)formar ingovernáveis extraviados, na tentativa de inscrever suas condutas no modelo econômico de existência, o governo das condutas parece traduzir-se em uma pedagogia das condutas, em uma pedagogia corporal. O entendimento do governo das condutas como pedagogia parece oferecer uma pista importante para analisar o funcionamento dos serviços substitutivos de saúde mental, em particular: o serviço, seu espaço, as prescrições clínico-institucionais que o regem, as diferentes atividades ali realizadas, as relações entre as pessoas que vivem, convivem e ali circulam, o modo como elas se comportam ali dentro, os saberes e fazeres que ali se desenvolvem, o cuidado ali oferecido, os projetos terapêuticos ali construídos parecem operar como pedagogias, como elementos formadores de condutas: gestos são inscritos nos corpos, processos de ensinoaprendizagem ali se tecem, organizando corpos, constituindo sujeitos ${ }^{9}$, ou seja, formando profissionais e usuários/as, personagens que ali se encontram, "cada um com uma função, um lugar, um rosto bem-definido" (Foucault, 2010, pp. 285286).

Mas se os CAPS figuram como territórios de ensino, na medida em que o ensinar se refere a processos por meio dos quais se almeja governar condutas, e a clínica em saúde mental tende a figurar como uma pedagogia de formatação corporal, observando os relevos desses serviços, bem ali saltam acontecimentos clínicos. Ali, pululam fagulhas saltitantes 
que reconfiguram o espaço (trans)formando-o em território afeito a (des)aprendizagens. Em outros termos, espreitando-se um pouco mais o cotidiano das práticas que povoam os CAPS, parecem explodir aqui e ali acontecimentos, produzindo o descaminho, ou pelo menos um caminho ainda por se construir para os corpos, para a vida, para a educação e para o cuidado ali produzido. Em outros termos, bem ali junto a processos que fazem destes serviços um território de ensino, de organização de corpos de profissionais e usuários/as, prescrevendo-lhes fôrmas-de-ação (Barros, 2005), bem ali aprendizagens escapam ao governo das condutas, criando possibilidades de singularização, de recusa a determinados modos de condução obstinados pela fabricação de rostos e fixação de funções e identidades institucionais. Bem ali, bifurcando essa busca pelo homogêneo que pauta o ensinar, corpos experimentam processos de aprendizagem que possibilitam sua abertura, corpos aprendem a desaprender. Nessa direção, Paraíso (2011, p. 47), assinala que:

[...] Aprender é abrir-se e refazer os corpos, agenciar atos criadores, refazer a vida, encontrar a diferença de cada um e seguir um caminho que ainda não foi percorrido. Aprender é abrir-se à experiência com "um outro", com "outros", com uma coisa qualquer que desperte o desejo. Por isso, para aprender é necessário "primeiro aprender a desaprender" (Caieiro, 1986). Aprender a desaprender os sentidos constituídos, os significados produzidos e os pensamentos construídos para abrir em si próprio as diferenças. Aprender é, em síntese, deixar-se “afetar” (Spinoza, 2007).

A partir de tais considerações, pode-se pensar os CAPS como territórios de ensino e organização de corpos, mas também como territórios onde se pode aprender a desaprender, a desnaturalizar todo um longo histórico de enlatadas aprendizagens sobre processos de cuidado. Dessa forma, pode-se experimentar processos de aprendizagem menos afeitos ao governo das condutas, à fixação identitária e à formatação subjetiva, mais interessados em abrir os corpos para a mestiçagem de encontros. Abrir-se a aprendizagens situadas bem ali no encontro sem bússolas com outros corpos e com o 'outro' do corpo. Esse 'ensaio' parece, assim, se configurar como:

[...] tarefa ético-política irredutível de qualquer tipo de intervenção que não se pretenda fascista: a prontidão à experiência de um encontro com a alteridade movente e, portanto, em estado de recomposição constante; encontro compreendido não como militância de uma causa transcendente qualquer, mas como prática intensificadora 
de uma arte geral de convívio marcado por nenhuma volúpia governamentalizadora e alguma porosidade à diferença e à variância que esse tipo de acontecimento pode nos provocar,ou ao que quer que a alteridade nos afete e nos faça descolar. Descaminhos da experiência de si, portanto (Aquino, 2011, p. 205).

\section{Corpo: a grande razão da clínica}

Ao nos referirmos à ampliação da clínica, atentamos para as questões apresentadas por Paulon (2004), ao problematizar a que $(\mathrm{m})$ destina a adjetivação da clínica como ampliada: "afinal trata-se de ampliar o que? Por quê? Em que sentido e com quais meios?" (2004, p. 259). Dito de outra maneira, quando se trata de fazer clínica em saúde mental, e do objetivo de articular esse fazer com a produção de corpos, parece ser preciso atentar para a discussão da encomenda institucional comumente feita aos/às trabalhadores/as de saúde mental, acerca do cuidado e do corpo. Que encomenda é essa? Atende a quem? A que objetivos no jogo das relações de poder? Atende ao escopo de condução das condutas rumo à reabilitação e participação na economia social de mercado? Pode atender a um movimento coletivo de insistência da desinstitucionalização como transvaloração (Paulon, 2006), como perturbação das coordenadas sócioculturais-corporais vigentes, pois $\mathrm{O}$ importante é tentar, mesmo o impossível (Amado, 2008). A esse respeito, aponta Paulon (2004, p. 265):

\begin{abstract}
Se ficarmos, então, discutindo a ampliação no âmbito da intervenção de uma Clínica meramente disseminadora dos mesmos modos de subjetivação existentes, estaremos, no máximo, ampliando os pontos de tensionamento entre um campo de saber que resiste a reconhecer seus sinais de esgotamento e as demandas do contemporâneo que poderiam indicar exatamente onde eles estão.
\end{abstract}

A clínica que desejamos insistir experimentando, uma clínica que vez em quando se insurge borrando a ortopedia de certas paisagens terapêuticas, desfazendo o aparentemente óbvio de uma clínica inclinada à formatação dos corpos, é uma clínica afeita a (des)aprendizagens, a novas feituras do seu próprio corpo. Uma clínica das passagens corporais, clínica da experimentação, feita por entre encontros de corpos. Na medida em que experimentamos formas potentes de fazer clínica justamente ali no encontro entre corpos e com o outro do corpo, inclusive o outro do corpo da clínica em saúde mental, é que apontamos nesse texto à ampliação da clínica por meio do operador corpo. 
Para tanto, cabe a advertência de não encerrar o corpo em qualquer uma destas concepções: nem biológico, nem psico, nem social, nem biopsicossocial, pois, como aqui discutimos, estamos falando de um corpo que se ergue por entre os desígnios do biológico e da linguagem, os quais não acompanham a velocidade e as intensidades que participam de sua feitura. Um corpo que nasce dos estratos, mas que é mais que essa paisagem instituída, um corpo capaz de transmutá-la. Enquanto se tenta, inclusive por meio de práticas clínicas, paralisar o corpo em estratos, ele foge, bifurca, cria uma saída, ou uma nova entrada, devém estrela e dança (Nietzsche, 1885/2008), situando-se a passos largos de quaisquer tentativas de interpretá-lo, representá-lo. Quando se pretende pensar corpo estagnando-o em uma destas concepções ou organizando-o mediante os marcadores sócio-culturais vigentes, seu movimento tende a cessar. Luz demais sobre um corpo que dança na escuridão tende a cegar. Eis o principal adoecimento: o do olhar de certas práticas clínicas que tomam o corpo como objeto a ser iluminado por tecnologias de poder.

Nesse contexto, uma clínica que se quer (re)existência precisa seguir o corpo em suas intensidades movediças, o que requer uma clínica igualmente movediça. Nesse sentido, a escuta precisa ser mais do que qualificada, mas sensível ao "corpo vibrátil", uma escuta dos movimentos intempestivos dos corpos e não restrita à mera aferição de normalidade dos comportamentos, tentando-se encaixar as necessidades do/a usuário/a aos ditames do mercado e do Estado: voltar a trabalhar, voltar a ter um corpo 'são' apto para um trabalho esvaziado de sentido, apto para o consumo, apto para se fazer um corpocapital, empreendedor de si. "Fico pensando por onde anda nossa tão promulgada capacidade de escutar e tão procurada possibilidade de se deixar afetar pelo outro", por seu corpo, por seus territórios, por sua forma de vida, mais que isso, pelo outro do corpo, dos territórios e da vida (Paulon, 2004, p. 265).

Uma clínica das passagens aponta para a necessidade de se experimentar uma escuta que busque pelo encontro, e não pela palavra, menos ainda por uma palavra justa (Deleuze, 1992), colada aos grandes clichês da saúde mental. Ressalte-se o caso da produção de cidadania, quando comumente o que se produz no terreno do capitalismo, é uma "cidadania da sujeição" (Carvalho, 2009), em que é preciso aderir ao quadro das boas condutas para se tornar cidadão/ã. Talvez, uma escuta atenda aos ilimitados modos de feitura de um corpo, interessada por sua abertura, pode abrir a clínica para outras experimentações de 
cidadania: ao invés de uma "cidadania da sujeição", a qual requer (auto)policiamento das condutas, que organiza os corpos colando-os a um rosto homogêneo e transcendental de homem e humanidade, junto ao corpo e às suas vibrações, ensaiase uma cidadania que brota não mais de identidades soberanas, mas imanente a processos singulares, num movimento associado às práticas cotidianas.

Conhecemos muito pouco do corpo. Tentamos, a todo momento, fixá-lo, formatá-lo, classificá-lo, representá-lo, como se uma forma, uma substância, uma palavra, um discurso, um saber pudesse bastar, acalmando nossas angústias de não saber de antemão o que é, o que pede e o que pode um corpo. Tendemos, inclusive, a desprezá-lo, corroborando com toda uma tradição filosófico-política que o rechaçou, posto que apegada a valores 'superiores' em detrimento da terra e do corpo. Daí as práticas clínicas tenderem a ser tão apegadas ao verbo, à tomada de consciência, ao alcance de uma suposta identidade interiorizada. $\mathrm{O}$ desprezo pelo corpo fez dele um prisioneiro de formatações. Nesse sentido, ao invés da alma, não seria o corpo que seria preciso libertar?

Porém nesse processo de libertação do corpo, cabe outra advertência: não se trata de uma tomada de consciência do corpo, como se a partir desta pudéssemos dizer o que por ele passa, pois “poderíamos passar sem a consciência [uma vez que] [...] em quase todos os processos fisiológicos fundamentais da vida vegetativa, e mesmo sensitiva, está ausente a qualidade psíquica da consciência" (Giacoia Jr., 2001, p. 31). A consciência mais atrapalha do que ajuda na compreensão do corpo como potência, principalmente, se ela não for utilizada como uma ferramenta, uma "ferramenta da mesma maneira como o estômago é uma ferramenta para digestão" (Giacoia Jr., 2002, p. 200).

Nesse sentido, Nietzsche (1885/2008) considera o corpo como "a grande razão" e a consciência apenas como um de seus órgãos. Por isso, o combate à organização do organismo. Por isso, construir um Corpo sem Orgãos para si, ao invés de tomar consciência de si. Por isso, a incitação ao descaminho, inclusive do corpo da clínica, por isso, mais do que saber o que se é, parece ser preciso recusar o que somos. "Em uma ironia socrática, conhecer-se a si mesmo, na medida em que significa tomar-consciência-de-si, implica em perder-se de si mesmo" (Giacoia Jr., 2001, p. 40).

Desse modo é que se pensou na possibilidade do corpo como operador da ampliação da clínica, entendendo o 
trabalho clínico como articulado aos movimentos de abertura e (des)aprendizagens corporais. A aposta é numa montagem clínica artesanal e singular, pouco afeita a especialismos, prescrições e generalizações, uma clínica que dê passagem aos movimentos corporais. Clínica que se tece bem ali em paisagens corporais noturnas, habitantes de fronteiras, borrando os caminhos instituídos para o corpo humano e suas condutas, dando possibilidade de emergência e territorialização de outras formas de feitura corporal. Clínica-corpo que somente será sabida e experimentada na medida em que se engendrar bem ali na imanência de práticas cotidianas.

A partir de tal entendimento, ao invés de se seguir dizendo do que necessitam corpos de usuários/as, a partir de tal ou qual diagnóstico, prescrevendo tal ou qual atividade, tal ou qual conduta, talvez se possa suspender certezas sobre seus corpos e sobre o corpo da clínica e experimentar uma prática clínica que trabalhe justo a potência dos corpos ao invés de vampirizá-los em favor do biopoder. Uma clínica que se lança em abertura para o descaminho de pensar e experimentar o corpo antes de ter forma, possibilitando novas montagens, inclusive terapêutica: “a clínica se revela, então, como a bricolagem de fragmentos que ora se conectam produzindo uma figura, ora se desconectam desestabilizando figuras constituídas" (Araújo, 2006, p. 21). O que se pensa com a clínica aqui esboçada é na constituição de habitações corporais que sejam menos restritivas, mais singularizantes e que, ao ousar desterritorializações, consigam materialidade de expressão, compondo novas formas.

Para tanto, aqui se pensou numa ética da clínica, no sentido de dar-lhe formas encarnadas por meio do que lhe indica relevos do contexto em que ela se desenrola, uma clínica tecida por meio do encontro entre corpos e com o outro do corpo, uma clínica da (des)aprendizagem, da abertura dos corpos para outras rotas, uma clínica experimentada como passagem, "uma experiência do limite" (Passos \& Benevides, 2006, p. 13), inclusive da própria clínica. Um cuidado que habite a tensão entre formatações e experimentações corporais e que, ao se desligar, pelo menos por alguns instantes, do mandato de sujeição de corpos, pode agenciar paisagens corporais singularizantes, um cuidado, que ao colocar sua própria vida à prova, pode agenciar outras formas de vida para os corpos.

\section{Notas}


1 Texto inédito, baseado em nossas pesquisas de mestrado e doutorado junto ao Programa de Pós-Graduação em Educação/UFRGS, financiadas pelo CNPq e pela CAPES.

${ }^{2}$ Os residenciais terapêuticos são serviços previstos pela Política Nacional de Saúde Mental/SUS, destinados para moradia de usuários egressos de longos anos de internação em hospitais psiquiátricos. O objetivo é o de reintroduzi-los no convívio social, tecendo um processo de cuidado articulado às equipes de atenção básica e à equipe do CAPS de referência para localidade de suas casas (Brasil, 2004).

3 “O organismo não é o corpo, o $\mathrm{CsO}$, mas um estrato sobre o $\mathrm{CsO}$, quer dizer um fenômeno de acumulação, de coagulação, de sedimentação que lhe impõe formas, funções, ligações, organizações dominantes e hierarquizadas, transcendências organizadas para extrair um trabalho útil" (Deleuze e Guattari, 1996, p. 21).

4 Nesse CAPS, nos inserimos como: apoiadora institucional do serviço (mais informações a esse respeito, ver Vasconcelos \& Morschel, 2009) e como coordenador do Projeto Movimentos. Tal projeto foi transversal e transdisciplinar, desenvolvido no período de abril de 2007 a fevereiro de 2009. Teve como finalidade produzir, na rede de saúde mental e suas interfaces, espaços coletivos de ação e de discussão acerca da temática do corpo (Mais detalhes a esse respeito, ver Machado, 2011).

5 Tais oficinas se caracterizam como espaços que se querem terapêuticos centrando-se em, pelo menos, três princípios: 1) Produzir cotidianidade, desenvolvendo atividades que costumam compor o cotidiano das pessoas (atividades da vida diária), tais como cozinhar, ter hábitos básicos de higiene, se embelezar etc. 2) Produzir coletivos, garantindo espaços de socialização, de troca de experiências, a partir de um envolvimento grupal com objetivos compartilhados: aprender ou implementar uma atividade. 3) Compor territórios existenciais, complexificando-os por meio da introdução de novas atividades, as quais tendem a funcionar como produtoras de novas paisagens subjetivas. Para isso, atividades artísticas e práticas corporais parecem ser imprescindíveis, janelas para si e para o mundo.

6 Não-lugares "desencorajam a ideia de 'estabelecer-se' [...] aceitam a inevitabilidade de uma adiada passagem, às vezes muito longa, de estranhos, e fazem o que podem para que sua presença seja 'meramente física' e socialmente pouco diferente, e preferencialmente 
indistinguível da ausência, para cancelar, nivelar, ou zerar as idiossincráticas subjetividades de seus "passantes", (Bauman, 2001, p. 119).

${ }^{7}$ Mais detalhes sobre essa discussão, ver Vasconcelos (2013).

${ }^{8}$ Vale dizer que, nesse texto, entende-se que tais investimentos educacionais são compostos por todo um conjunto de processos por meio dos quais indivíduos são transformados em sujeitos de uma determinada cultura, em terrenos de capitalismo financeiro, em sujeitos de uma dada cultura somático-empresarial. Tornarse sujeito dessa cultura envolve um complexo de processos de ensino e de aprendizagem que permeiam muitas instâncias e dimensões da vida em sociedade. Em outras palavras, não se separa aqui educação de socialização.

9 "Você será organizado, você será um organismo, articulará seu corpo - senão será um depravado. Você será significante e significado, intérprete e interpretado senão será desviante. Você será sujeito e, como tal, fixado, sujeito de enunciação rebatido sobre um sujeito de enunciado senão você será apenas um vagabundo" (Deleuze \& Guattari, 1996, p. 22).

\section{Referências}

Alvarez, J. \& Passos, E. (2009). Cartografar é habitar um território existencial. In E. Passos, V. Kastrup, \& L. Escóssia (Org.). Pistas do método da cartografia: pesquisa-intervenção e produção de subjetividade (pp. 131-149). Porto Alegre: Sulina.

Amado, J. (1961/2008). A morte e a morte de quincas berro dágua. São Paulo: Companhia das Letras.

Antunes, A. (1993). Agora. Em nome. Bmg.

Aquino, J. G. (2011). A governamentalidade como plataforma analítica para os estudos educacionais: a centralidade da porblematização da liberdade. In G. C. Branco, \& A. Veiga-Neto. (Org.). Foucault: filosofia \& política (pp. 195211). Belo Horizonte: Autêntica.

Araújo, F. (2006). Um passeio esquizo pelo acompanhamento terapêutico: dos especialismos à clínica da amizade. Niterói, RJ: Editoração Eletrônica.

Artaud, A. (1983). Para acabar com o julgamento de deus. In A. Artaud. Os escritos de antonin artaud (C. Willer, Trad., pp. 145-162). Porto Alegre: LPM.

Barros, M. E. (2005). Desafios ético-políticos para a formação dos profissionais de saúde: transdisciplinaridade e integralidade. In R. Pinheiro, \& R. Ceccim (Org.). Ensinar saúde: a integralidade e o sus nos cursos de graduação na área da saúde. (pp. 131152). Rio de Janeiro: Ims/Uerj, Cepesq, Abrasco. 
Bauman, Z. (2001). Modernidade líquida. Rio de Janeiro: Jorge Zahar Editor.

Brasil, Ministério da Saúde. (2002). Portaria GM $n^{o}$ 336. Brasília: Ministério da Saúde. (2004). Residências terapêuticas: o que são, para que servem. Brasília: Ministério da Saúde. - (2008). Documento base para gestores e trabalhadores do sus ( $4^{\mathrm{a}} \mathrm{ed}$.). Brasília: Editora do Ministério da Saúde. (2010). Ambiência. ( $2^{\mathrm{a}}$ ed.). Brasília: Editora do Ministério da Saúde. Carvalho, S. R. (2009). Reflexões sobre o tema da cidadania e a pordução de subjetividade no SUS. In S. R. Carvalho, M. E. Barros, \& S. Ferigato (Org.). Conexões: saúde coletiva e políticas da subjetividade (pp. 23-41). São Paulo: Aderaldo \& Rothschild.

Deleuze, G. (1992). Conversações (19721990). São Paulo: Ed. 34 (coleção trans). (2005). Foucault. São Paulo: Brasiliense.

Deleuze, G. \& Guattari, F. (1996). Mil plâtos: capitalismo e esquizofrenia (vol. 3). Rio de Janeiro: Editora 34.

(1997). Mil platôs: capitalismo e esquizofrenia (vol. 4). São Paulo: Ed. 34.

Duarte, A. (2009). Focault e as novas figuras da biopolítica. In M. Rago \& A. VeigaNeto (Org.). Para uma vida não-facista (pp. 35-50). Belo Horizonte: Editora Autêntica.
Escóssia, L. (2009). O coletivo como plano de criação na saúde pública. Revista Interface - comunicação, saúde e educação, 689-694.

Foucault, M. (2001b). História da sexualidade I: a vontade de saber (14 ed.). Rio de Janeiro: Edições Graal. (2001a). Microfísica do poder (16 ed.). Rio de Janeiro: Graal.

(2006). A vida dos homens infames. In M. B. Motta. Estratégia, saber-poder. Ditos \& escritos IV (pp. 203-222). Rio de Janeiro: Forense Universitária.

(2010). O sujeito e o poder. In H. L. Dreyfus, \& P. Rabinow. Michel foucault: uma trajetória filosófica: para além do estruturalismo $e \quad d a$ hermenêutica (2.ed., pp. 273-295). Rio de Janeiro: Forense Universitária. . 1979-1980 (2011). Do governo dos vivos. In N. Avelino. São Paulo/Rio de Janeiro: Centro de Cultura Social/Achiamé.

Giacoia Jr., O. (2001). Nietzsche como psicólogo. São Leopoldo/RS: Editora Unisinos. (2002). Resposta a uma questão: o que pode um corpo? In D. Lins, \& L. Gadelha (Org.). Nietzsche e Deleuze: que pode o corpo (pp. 199-216). Rio Janeiro/Fortaleza: Relume Dumará, Secretaria da Cultura de Desporto.

Guattari, F. \& Rolnik, S. (2000). Micropolítica: cartografias do desejo ( $6^{\mathrm{a}}$ ed.). Petrópolis: Vozes. 
Kastrup, V. (2007). O funcionamento da atenção no trabalho do cartógrafo. Psicologia \& Sociedade, 19 (1), 15-22.

Le Breton, D. (2007). A sociologia do corpo ( $2^{\mathrm{a}}$ ed.). Petrópolis, RJ: Vozes.

Lourau, R. (1995). A análise institucional. Petrópolis, RJ: Vozes.

Louro, G. L. (2004). Um corpo estranho. Belo Horizonte: Autêntica.

Machado, D. (2011). Movimentos na educação física: por uma ética dos corpos. Dissertação (Mestrado). Universidade Federal do Rio Grande do Sul. Porto Alegre.

Mauss, M. (1974). Noção de técnica corporal. In: Sociologia $e$ antropologia. São Paulo: e.p.u. editora pedagógica e universitária ltda.

Meyer, D. E. (2009). Corpo, violência e educação: uma abordagem de gênero. In R. D. Junqueira (Org.). Diversidade sexual na educação: problematizações sobre a homofobia nas escolas (pp. 213233). Brasília: Ministério da Saúde/Unesco.

Nietzsche, F. (1885/2008). Assim falou zaratustra (17a ed.). Rio de Janeiro: Civilização Brasileira.

Orlandi, L. B. (2009). Ética em Deleuze. Acesso em 10 de 05 de 2010, disponível em café filosófico: http://www.cpflcultura.com.br/site/2009/ 10/15/integra-etica-em-deleuze-luiz-b-1orlandi/

Ortega, F. (2008). O corpo incerto: corporeidade, tecnologias médicas e cultura contemporânea. Rio de Janeiro: Garamond.

Paraíso, M. A. (2011). Raciocínios generificados no currículo escolar e possibilidades de aprender. In Leite, C. (Org.). Políticas, fundamentos e práticas do currículo. (pp. 147-160). Porto: Porto Editora.

Passos, E. \& Benevides, R. (2006). Prefácio. In F. Araújo. Um passeio esquizo pelo acompanhamento terapêutico: dos especialismos à política da amizade (pp. 13-14). Niterói, RJ: Editoração eletrônica.

Paulon, S. M. (2006). A desinstitucionalização como transvaloração: apontamentos para uma clínica do niilismo. Revista Athenea digital, 121-136. . (2004). Clínica ampliada: que(m) demanda ampliações? In T. Fonseca, \& S. Engelman. Corpo, arte e clínica (pp. 259-274). Porto Alegre: Editora da UFRGS.

Sant'anna, D. B. (2001). Corpos de passagem: ensaios sobre a subjetividade contemporânea. São Paulo: Estação Liberdade.

Vasconcelos, M. \& Morschel, A. (2009). O apoio institucional e a produção de redes: do desassossego dos mapas vigentes na saúde coletiva. Revista Interface, 13(supl. I), 729-738.

Vasconcelos, M. (2013). A infâmia de quincas. (re)existências de corpos em tempos de biopolítica. Tese (Doutorado). 
Universidade Federal do Rio Grande do Sul. Porto Alegre.

Veiga-Neto, A. (2001). Incluir para excluir. In

J. Larrosa, \& C. Skliar. Habitantes de babel. Políticas e poéticas da diferença (pp. 105-118). Belo Horizonte: Autêntica.

\section{Dagoberto Oliveira}

Graduação em Educação Física (FACED/UFRGS), mestrado em Educação (PPGEDU/UFRGS), consultor da Política Nacional de Humanização/Ministério da Saúde.

E-mail: dagoesef@gmail.com

\section{Michele Vasconcelos}

Graduação em Psicologia (UFS), mestrado em Saúde Coletiva (Instituto de Saúde Coletiva/UFBA), doutorado em Educação (PPGEDU/UFRGS), consultora da Política Nacional de Humanização/Ministério da Saúde.

E-mail: michelevasconcelos@hotmail.com

\section{Aldo Rezende de Melo}

Graduação em Psicologia (UFS), mestrando em Psicologia Social (UFS), apoiador institucional da Diretoria Operacional da Fundação Hospitalar de Saúde de Sergipe (FHS) e coordenador do Comitê de Humanização da FHS.

E-mail: aldoufs@hotmail.com 